\title{
Quantitative analysis of language production in Parkinson's disease using a cued sentence generation task
}

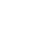

(1)

(1)

(1)

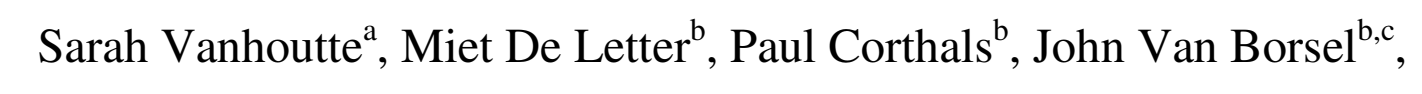

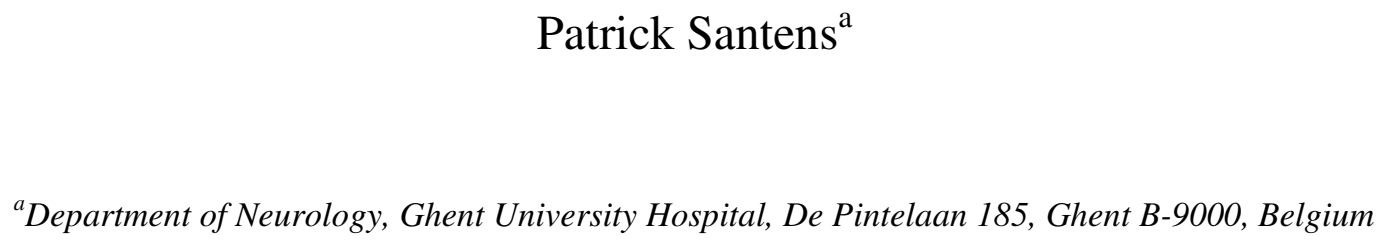

Patrick Santens $^{\mathrm{a}}$

${ }^{a}$ Department of Neurology, Ghent University Hospital, De Pintelaan 185, Ghent B-9000, Belgium
${ }^{b}$ Department of Oto-Rhino-Laryngology and Logopaedic/Audiologic Sciences, Ghent University Hospital, De Pintelaan 185, Ghent B-9000, Belgium
${ }^{c}$ Universidade Veiga de Almeida, Rio de Janeiro, Brazil

Corresponding author: Miet De Letter

E-mail address: miet.deletter@ugent.be

Keywords: Parkinson's disease, language, language analysis, cognition, language production, executive functions 
1 The present study examined language production skills in Parkinson's disease (PD) patients. A unique

2 cued sentence generation task was created in order to reduce demands on memory and attention.

3 Differences in sentence production abilities according to disease severity and cognitive impairments

4 were assessed. Language samples were obtained from 20 PD patients and 20 healthy control

5 participants matched for age, sex and educational level. In addition, a cognitive test for verbal memory

6 and resistance to cognitive interference was administered. Statistical comparisons revealed significant

7 language changes in an advanced stage of the disease. Advanced PD patients showed a reduction in

8 lexical diversity in notional verbs, which was absent in nouns. Cognitive dysfunctions such as

9 impaired verbal memory are suggested to contribute to the typical noun/verb dissociation in PD

10 patients. In addition, advanced PD patients produced more semantic perseverations, which may be related to set-switching problems. In conclusion, whether language disturbances in PD are the result of non-linguistic cognitive dysfunctions or reflect pure language deficits exacerbated by cognitive impairments, remains a matter of debate. However, the negative impact of cognitive dysfunctions may be important.

Keywords: Parkinson's disease, language, language analysis, cognition, language production, executive functions 


\section{$1 \quad$ Introduction}

2 Parkinson's disease (PD) is a progressive, neurodegenerative disorder with an estimated prevalence of around 3/1000 in the general population and 1/100 in individuals over 60 years (Morgante, Rocca, Di Rosa, De Domenico, Grigoletto, Meneghini et al., 1992; de Rijk, Breteler, Graveland, Ott, Gobbee, van der Meché et al., 1995; Samii, Nutt, \& Ransom, 2004). In PD, neurodegeneration in the substantia nigra causes dopamine depletion in the striatum which disrupts basal ganglia-thalamocortical circuits (Alexander, DeLong, \& Strick, 1986). Although PD is traditionally viewed as a motor disease, nonmotor and cognitive symptoms may occur as well (Gelb, Oliver \& Gilman, 1999; Caballol, Marti, \& Tolosa, 2007; Piovezan, Teive, Piovesan, Mader, \& Werneck, 2007; Ziemssen \& Reichmann, 2007; Alves, Forsaa, Pedersen, Gjerstad, \& Larson, 2008; Jankovic, 2008). Communication is affected in a substantial proportion of PD patients. Speech and voice disorders occur in approximately 89\% (Trial, Fox, Olson Ramig, Sapir, Howard, \& Lai, 2005). In addition, pragmatic disorders (McNamara \& Durso, 2003) and sentence comprehension difficulties have been reported. Besides disturbed thematic role mapping (Whiting, Copland, \& Angwin, 2005) impairments occur in processing complex syntactic structures (e.g. passives, sentences with center embedded clauses) and ambiguous or metaphoric information (McNamara, Krueger, O’Quin, Clark, \& Durso, 1996; Lewis, LaPointe, Murdoch, \& Chenery, 1998; Grossman, 1999; Murray \& Stout, 1999). With regard to language production, most studies are restricted to single-word production. Phonologic and semantic fluency tasks yield conflicting results due to large differences in tasks and participants (Raskin, Sliwinski, \& Borod, 1992; Flowers, Robertson \& Sheridan, 1995; Signorini \& Volpato, 2006). More agreement can be found in studies addressing verb production. Both action fluency and action naming (compared to noun naming) are often reported to be impaired. Whether this is the consequence of a grammatical deficit (Péran, Rascol, Démonet, Celsis, Nespoulous, Dubois et al., 2003), a problem in accessing mental representations of actions (Péran et al., 2003; Boulenger, Mechtouff, Thobois, Brousolle, Jeannerod \& Nazir, 2008; Rodriguez-Ferreiro, Menendez, Ribacoba, \& Cuetos, 2009; Herrera \& Cuetos, 2012), an executive dysfunction (Piatt, Fields, Paolo, Koller, \& Tröster, 1999; Signorini \& Volpato, 2006; Cotelli, Borroni, Manenti, Zanetti, Arévalo, Cappa et al., 2007; Colman, Koerts, van 
Beilen, Leender, Post, \& Bastiaanse, 2009) or a combination of both (Péran et al., 2003) is a matter of debate. Decreased activation of the frontal cortex, due to reduced stimulation from the basal ganglia, is considered to be the common underlying mechanism (Cotelli et al., 2007).

In contrast to single-word production, only a few studies examined high level language production, which is language production on sentence- or discourse level. Analysis of spontaneous speech samples revealed a decline in the percentage of syntactically correct sentences, grammatical complexity, sentence length and informativeness of the utterances in non-demented PD patients (Cummings, Darkins, Mendez, Hill \& Benson, 1988, Murray, 2000). Another research group described a reduction in syntactic complexity, distinguishing mild from moderate PD patients and strongly correlating with the severity of the dysarthria (Illes, Metter, Hanson, \& Iritani, 1988; Illes, 1989). Although this suggests that linguistic deterioration is part of the disease process, the higher amount of lexical words found in more advanced patients contradicted this assumption. Therefore, another hypothesis was formulated: when the severity of the disease and the dysarthria progresses, PD patients compensate for their articulatory difficulties by producing more lexical phrases and fewer interjections and modalizations, since it would be inefficient to produce non-informative speech.

A more recent study evaluated spontaneous speech in bilingual participants. More grammatical errors and a simplified syntax were observed in PD patients compared to control participants, but only in the first language (Zanini, Tavano, \& Fabbro, 2010). This observation is attributed to differences in the neural representations of the languages as a consequence of differences in age of acquisition. While the first language is learned implicitly from childhood on, engaging basal ganglia structures, the second language is learned more explicitly, engaging neocortical representations. Since PD is a disorder in basal ganglia structures, implicitly learned grammar can be more disturbed than explicitly learned grammar.

Not all studies confirmed dysfunctional language production skills in PD patients. In a written sentence task, no discrepancy between non-demented PD patients and control participants was observed (Small, Lyons, \& Kemper, 1997). The absence of any language impairment is argued to relate to the demand characteristics of the task used to collect language samples. In the 
abovementioned studies, PD patients engaged in conversation or described a picture which sets higher demands on memory and attention than this sentence writing task. Since these cognitive functions are often impaired in PD (Caballol et al., 2007; Piovezan et al., 2007), PD patients possibly simplified their sentences during spontaneous speech in order to maintain sufficient memory and attentional resources to complete the task. During the sentence writing task, this simplification was not necessary because this design sets low demands on cognition (Small et al., 1997).

Cognitive deficits occur frequently in PD even in the early stages of the disease (Lees \& Smith, 1983; Levin, Labre, \& Weiner, 1989; Cooper, Sagar, Jordan, Harvey \& Sullivan, 1991). Visuospatial functioning, memory and executive functions are particularly affected (Dubois \& Pillon, 1997). Language production may rely on these cognitive abilities (Lewis et al., 1998). Indeed, language and cognition interactions have been reported in PD patients. Both language comprehension (Lieberman, Friedman, \& Feldman, 1990; Grossman, Cooke, DeVita, Lee, Alsop, Detre et al., 2003; Hochstadt, 2009), language production on a single-word level (Péran et al., 2003; Signorini \& Volpato, 2006; Cotelli et al., 2007) and language production on sentence and discourse level (Murray, 2000; Murray \& Lenz, 2001; Berg, Björnram, Hartelius, Laakso, \& Johnsels, 2003; Zanini et al., 2010) correlated with executive dysfunctions such as working memory, sequencing and set-switching. These observations led to the assumption that impaired language performance in PD did not reflect merely a language problem, but rather the impact of PD on non-linguistic cognitive functions (Bayles, 1990; Bayles, Tomoeda, Wood, Cruz, Azuma, \& Montgomery, 1997). Specific linguistic deficits secondary to the disease would not exist (Bastiaanse \& Leenders, 2009). Other researchers disagree with this suggestion and hypothesize that PD causes pure language deficits which can be exacerbated by cognitive impairments (Altmann \& Troche, 2011).

Unfortunately, many of the tasks that have been used for the evaluation of language put relatively high demands on cognitive functions. As a consequence, cognitive dysfunctions may have worsened or even elicited linguistic problems. Therefore, the present study aimed at examining high-level language production skills in PD patients while cognitive demands were lowered. For this purpose, a specific cued sentence generation task was created. Several changes were implemented to decrease attention 
and memory influence. The language samples collected were evaluated by performing a standardized language analysis assessing sentence length, characteristics of verbs and nouns, and grammatical correctness of the sentences. Some other variables, similar to previous studies, were considered as well: the proportion of lexical and function words (Illes et al., 1988; Illes, 1989), and the proportion of complex and simple sentences (Murray, 2000). In addition, the informativeness of the sentences was judged. Murray, (2000) reported a decline in informativeness during spontaneous speech. Utterances were considered uninformative if they contained incomplete, irrelevant or inaccurate information, conveyed personal value judgments (e.g. This is ugly) or repeated previously stated information. The first two criteria were not applicable in the specific design of the present study. Therefore, only repetition of previously mentioned information was counted which is equal to counting verbal perseverations. Verbal perseverations have been observed in PD on single-word level (Lees \& Smith, 1983) and sentence level in demented patients (Bayles, Tomoeda, Kaszniak, Stern, \& Eagans, 1985). To the best of our knowledge, the occurrence of these phenomena on a sentence level has not been examined in non-demented PD patients.

Three main research questions were investigated: (1) Are there differences in sentence generation abilities between PD patients and normal healthy control participants? (2) Does disease severity influence sentence generation abilities in PD patients? Many studies tested PD patients in different stages of the disease (Azuma, Bayles, Cruz, Tomoeda, Wood, McGeagh et al., 1997; Muslimovic, Post, Speelman, \& Schmand, 2005; Williams-Gray, Foltynie, Brayne, Robbins, \& Barker, 2007; Elgh, Domellöf, Linder, Edström, Stenlud, \& Forsgren, 2009; Merola, Zibetti, Angrisano, Rizzi, Ricchi, Artusi et al., 2011; Reid, Hely, Morris, Loy, \& Halliday, 2012). Language seemed to deteriorate with disease progression. However, these language assessments were mainly restricted to single-word production in fluency and naming tasks. As far as we could ascertain only one research group addressed the impact of disease severity on connected speech in non-demented PD patients (Illes et al., 1988; Illes, 1989). A negative influence on syntactic complexity was observed. (3) Are there differences in sentence generation abilities between PD patients according to cognitive functioning? As mentioned above, cognitive deterioration in PD occurs particularly in visuospatial functions, 


\section{Methods}

\section{Participants}

memory and executive functions (Dubois \& Pillon, 1997). Especially the latter two may affect language production. Therefore, two cognitive tests were included to assess explicit verbal memory and resistance to cognitive interference, which is a measure of executive functioning.

Twenty right-handed PD patients (male/female ratio: 1/1, mean age: 64.3 years, age range: $45-84$ years) were recruited from the movement disorder consultation of the Ghent University Hospital. All were clinically diagnosed with idiopathic PD using the criteria by Gelb et al. (1999). PD staging based on the 'Hoehn \& Yahr scale' (1967) allowed a division into two subgroups: early stage (Hoehn \& Yahr 1 - 2) and advanced stage (Hoehn \& Yahr 3 - 5).

Only non-demented PD patients were included. The exclusion of dementia was performed by an experienced neurologist (PS), and was based on the DSM-IV criteria for dementia. In addition the Mini-Mental State Examination (MMSE) (Folstein, Folstein, \& McHugh, 1975) was administered in order to have an indication of general cognitive functioning. Deep brain stimulation (DBS) was an exclusion criteria too because its influence on language, cognition, behaviour and mood is still unclear (e.g. Dujardin, Defebvre, Krystkowiak, Bond, \& Destée, 2001; Funkiewiez, Ardouin, Caputo, Krack, Fraix, Klinger et al., 2004; Takeshita, Kurisu, Trop, Arita, Akimitsu, \& Verhoeff, 2005; Contarino, Daniele, Sibilia, Romito, Bentivoglio, Gianotti et al., 2007; York, Dulay, Macias, Levin, Grossman, Simpson et al., 2008). All PD patients were treated with regular anti-parkinson medications and were considered to be in a stable treatment regimen for at least one month before testing. The treatment regimen was continued throughout.

Twenty right-handed healthy individuals matched for age, gender and educational level (male/female ratio: 1/1, mean age: 63.0 years, age range: 49 - 82 years) served as a control group. All of them were cognitively normal (MMSE $\geq 27$ ). An overview of other characteristics can be found in table 1 . Participants were informed of the aim of the present study and gave their informed consent. This study was approved by the Ethical Committee of the Ghent University. 


\section{Procedure}

The language test was administered first, to avoid effects of fatigue as much as possible. Subsequently participants underwent three cognitive tests. These were randomized across participants but with control subjects receiving the same sequence as the PD patient with whom they were matched. All participants were tested by the first author in a quiet room with little distraction.

9

\section{Language assessment}

The present study aimed to assess language production on a broad sentential level, but with a restricted influence of cognition. For this purpose, a unique cued sentence generation task was created. Participants were asked to retell the text 'Meneer Meijer' from Logotherapia, a Dutch therapeutic program (Bonta \& Sistermans-Theunisse, 1993) however, with several adaptations in order to reduce memory and attention demands. First, the text (originally consisting of 20 sentences) was shortened to eleven sentences. Secondly, participants were allowed to read the text twice. Thirdly, cues were provided to facilitate reproduction. The cues consisted of ten lexical words from the text which were visually presented in chronological order. Participants were asked to dictate one sentence to the investigator for each given word. It was stressed that their sentences were not supposed to be identical to those of the text and should only render the general idea of the story. Cues were provided because PD patients are known to have impaired internal control, but more preserved external control (Brown \& Marsden, 1988). It was hypothesized that giving the external cues would help participants to retell the story. The analyses of the language samples did not focus on the correctness of the content of the sentences. Content errors were not taken into account. Therefore, providing cues did not confound the results of the language analysis. The investigator wrote down the dictated sentences. While administering the test, no feedback was given. To keep uniformity high, the same procedure was applied for control persons. Both the text and cues can be found in appendix A. 
Because no specific language battery is available for $\mathrm{PD}$, the standardized language analysis was based on a procedure for analysing spontaneous speech in aphasic patients, the ASTA (Analyse voor Spontane Taal bij Afasie, $=$ Analysis of Spontaneous language in Aphasia). The ASTA was developed by the "Vereniging voor Klinische Linguïstiek" (VKL) (= Society for Clinical Linguistics) in order to standardize the quantitative analysis of spontaneous language (Boxum \& Zwaga, 2007). The ASTA measures mean length of utterance (MLU), proportion of verbs (determined by dividing the number of verbs by the total number of words), type/token ratio (TTR) of notional verbs, proportion of nouns (determined by dividing the number of nouns by the total number of words), TTR of nouns and proportion of grammatical correct sentences (determined by dividing the number of grammatical correct sentences by the total number of sentences). Since a well-matched control group was included in the present research, the normative data of the ASTA were not taken into account.

Following previous research, some concomitant variables were assessed: proportion of lexical and function words (Illes et al., 1988; Illes, 1989) and proportion of simple and complex sentences (Murray, 2000). The distinction between simple and complex sentences was based on the number of predicates in the sentence. A simple sentence contained one predicate, a complex sentence comprised two or more predicates. In addition, the occurrence of verbal perseverations was evaluated by defining the proportion of semantic perseverations (See appendix B for some examples). Perseverations are often word-level errors. However, the measures TTR of verbs and nouns reflect repetitions of verbs and nouns respectively. Therefore, in the present study verbal perseverations were considered as a lexico-semantic measure. A perseveration was defined as an idea that is expressed more than once (Bayles et al., 1985). Their occurrence was determined using utterances instead of sentences. An utterance is a grammatical unit that expresses one thought. Since a simple sentence communicates one idea, the whole sentence corresponds with one utterance. A complex sentence on the other hand, comprises several ideas. Therefore, the main clause was separated from the subordinate clause(s). Each clause was equal to one utterance. Per utterance, it was judged whether the expressed idea was already mentioned or not. Since no information repeated in the text, this was a quite straightforward measure. Only the utterance that contained the repeated information was marked as a perseveration. 
1 The original sentence was not. Instead of just counting the number of perseverations, a ratio was

2 calculated because this takes the amount of utterances into account. The proportion of semantic 3 perseverations was than determined by dividing the number of perseverative utterances by the total 4 number of utterances.

5 To ascertain that participants did not repeat the sentences from the text literally, a second evaluator rated the degree of repetition independently. Both the original text and the dictated sentences were divided in utterances (the same as for perseverations). Per dictated utterance, it was determined if it was identical to an utterance of the original text. A percentage was then calculated by dividing the number of literal repeated utterances by the total number of dictated utterances. This percentage varied between $0-8,2 \%$ for the PD patients and between $0-9,1 \%$ for the control participants. Because this is quite low, it was concluded that there was no repetition effect.

As for reliability, the ASTA is considered to be a reliable and valid test. All variables show an interrater agreement exceeding 91\%, except 'proportion of grammatical correct sentences' which has $80 \%$ concordance (Flohil-v.d. Scheer, Zwaga, \& Jonkers, 2011). The measures of the ASTA were evaluated by one researcher, except the latter variable which was scored by two evaluators independently. Differences in scoring were then discussed to achieve consensus. All additional analyses were done by two evaluators too. Interrater-agreement was determined and varied between $92 \%$ and $100 \%$.

\section{Cognitive assessment}

Three cognitive tests were included in a randomised order. Mini-Mental State Examination (MMSE) (Folstein et al., 1975) was administered to assess general cognitive abilities. If MMSE score $\leq 24$, patients were excluded. Explicit verbal memory was evaluated by the Auditory Verbal Learning Test (AVLT) (Rey, 1964; Lezak \&Loring, 2004). The Stroop Colour Word Test (SCWT) (Stroop, 1935; Hammes, 1978) was included to define resistance to cognitive interference, a measure of cognitive control and inhibition (Lezak \& Loring, 2004; Strauss, Sherman, \& Spreen 2006). Participants performed the first three cards of the SCWT, but only the interference score was used for further 
analyses. Performance on cognitive tests depends on gender, age and educational level. Therefore, the results were compared with adapted normative values for the Flemish population that take these variables into account (Miatton, Wolters, Lannoo, \& Vingerhoets, 2004).

\section{Statistical analyses}

SPSS 17.0 was used for statistical analyses. To answer the first two research questions, three main analyses were performed. All language variables were included in every analysis. A first analysis compared all PD patients with all control participants. Subsequently, PD patients in advanced and early stage were compared with their respective control group. For both these analyses the MannWhitney U test, a non-parametric test, was used. Although PD patients and control participants were matched, a non-paired statistical test was preferred because the variability of the parameters between matched pairs was too large. A third analysis compared PD patients in early and advanced stage using a Mann-Whitney U test.

In order to investigate differences according to cognitive abilities, only the results of PD patients were analyzed. While normative values of the AVLT are expressed in an average score with a certain standard deviation (SD), norms of the Stroop test are expressed in percentiles. Both scoring systems do not allow a correlation analysis. Therefore, the PD group was divided into two subgroups for each cognitive test separately. These subgroups were compared with each other using a Mann-Whitney U test. For the AVLT, PD patients who scored within normal limits (between - 1 SD and + 1 SD) were assigned to the normal scoring group ( $\mathrm{n}=13)$. PD patients who scored more than one standard deviation below the average score were assigned to the poor scoring group $(n=7)$. For the SCWT, one patient was excluded from analysis because of difficulties distinguishing colours. 12 patients presented with a weak interference score (pc 0 - 49) and 7 patients with a good interference score (pc $50-100)$. Due to multiple comparisons, the probability of making a Type I error increased. Therefore, the number of statistical comparisons was reduced by excluding the proportion of function words and simple sentences from the statistical analyses. These variables are the inverse of the proportion of lexical words and complex sentences respectively and would have revealed the same result. 
Another procedure, often employed to reduce this probability, is Bonferroni correction. However, this statistical method is not without limitations. First, statistical power drops to $33 \%$ while the probability of making a Type II error remains very high (Nakagawa, 2004). Secondly, there is no consensus among statisticians for when this statistical procedure should be used (Perneger, 1998). And thirdly, the more measures are evaluated, the less probable it becomes to find significant results (Moran, 2003). For these reasons, Bonferroni corrections were not applied. Instead the level of significance was reduced to $\alpha \leq 0.01$. Results between 0.01 and 0.05 were considered as trends.

In addition, effect sizes were calculated, as suggested by Nakagawa (2004). Effect sizes show the experimental effect and are comparable across studies even if different sample sizes are used. In this study Cohen's $d$ was determined. Cohen's $d$ is positive if the mean difference between two groups is in the predicted direction. Consequently, when Cohen's $d$ is negative, the mean difference manifests in the opposite direction. However, for some language variables predicting a certain direction of the mean difference could not be based on objective facts. Therefore, the absolute value of the effect size is displayed. In table 2 and table 3, the mean and standard deviation for all language variables for all the groups are presented as well. In this way, the better scoring group can be determined. The values Cohen (1988) proposed for small, medium and large effects were applied: $|d|=0.20,0.50$, and 0.80 respectively.

Insert table 2 and table 3 about here

\section{Results}

In table 2, results of the comparisons between PD patients and control participants are shown. Only one difference was found between the entire PD group and the control participants: PD patients generated a higher proportion of semantic perseverations ( $p=.005$, Cohen's $d=.92)$. Analyses based on disease staging revealed that only advanced PD patients differed significantly from the control persons. These patients showed less diversity in notional verbs $(p=.01$, Cohen's $d=1.19)$. No significant difference was found in any morphosyntactical measure: MLU ( $p=.96$, Cohen's $d=.08)$, 
proportion of complex sentences ( $p=.67$, Cohen's $d=.15$ ) and proportion of grammatical correct sentences $(p=.70$, Cohen's $d=.40)$. In addition, no difference in the proportion of verbs $(p=.23$, Cohen's $d=.39$ ) and nouns ( $p=.57$, Cohen's $d=.22)$ was observed. Lexical-semantic analysis showed that advanced PD patients produced significantly more semantic perseverations than did their matched controls $(p=0.01$, Cohen's $d=1.26)$. Comparison of PD patients in the advanced and the initial stages showed a trend in the proportion of notional verbs. Moderately affected PD patients tended to produce more verbs than mildly affected patients ( $p=.04$, Cohen's $d=.67)$. Comparison between PD patients according to their score on the two cognitive tests, showed a significant reduction in TTR of the notional verbs ( $p=.01$, Cohen's $d=1.23$ ) in PD patients with poor verbal memory. For the SCWT, no significant difference was found between PD patients with a weak and a good interference score. Other results of the statistical comparison between PD patients according to disease progression and cognitive functioning are summarized in table 3.

\section{Discussion}

The present study aimed at examining cued sentence generation with minimized influence of attention and memory in PD patients. Possible differences according to disease staging and cognitive deterioration were explored as well. Twenty PD patients and twenty healthy normal controls retold a story in ten sentences, which were cued by single words from the text. A quantitative analysis was performed.

Results clearly demonstrate the usefulness of making a distinction according to disease severity. In the initial phase, sentence generation was not negatively affected by the presence of the disease. In contrast, advanced PD patients showed significant language changes compared to normal control participants. Remarkably, these disparities did not appear on morphosyntactical measures (MLU, proportion of grammatically correct sentences, proportion of complex sentences). This confirms a study that analyzed language production with a minor cognitive load (Small et al. 1997) and contradicts other studies that analyzed spontaneous speech, which requires more attention and memory (Cummings et al., 1988; Illes et al., 1988; Illes, 1989; Murray, 2000; Murray\& Lenz, 2001). In the 
present study, the influence of these cognitive functions was minimized. It would seem that when cognitive load is kept low, PD patients in both early and advanced phases of the disease are able to form grammatically correct sentences with normal complexity and sentence length. Note that this hypothesis does not exclude a primary morphosyntactical deficit in PD (Zanini et al., 2010). Low demands on memory and attention may possibly help them to overcome this deficit. Grossman et al. (2003) showed that PD patients can maintain accuracy on a language task, despite language problems, by up-regulating cortical activity.

Another aspect, namely time-pressure, might contribute to this observation as well. In spontaneous speech, continuity is known to be important which causes some time pressure. In the present study as well as in the study by Small et al. (1997) there was no such pressure. PD patients had time to think about their sentences before dictating or writing them. Reduction of time-pressure might help PD patients to preserve a correct syntax or to overcome morphosyntactical impairments. However, this remains hypothetical, as it was not evaluated in this study.

A significant difference between advanced PD patients and control participants was observed in the TTR of notional verbs. Advanced PD patients presented a decrease in lexical diversity in notional verbs, but not in nouns. This noun/verb dissociation has been reported extensively in both mildly and moderately impaired PD patients (Piatt et al., 1999; Péran et al., 2003; Signorini \& Volpato, 2006; Cotelli et al., 2007; Boulenger et al., 2008; Colman et al., 2009; Rodriguez-Ferreiro et al., 2009; Herrera \& Cuetos, 2012). The frontostriatal pathophysiology of PD is suggested to be the main cause (Cotelli et al., 2007). Dopamine depletion in the striatum disrupts the subcortical-prefrontal circuits and causes a dysfunction of the prefrontal cortex (Alexander et al., 1986). While prefrontal cortex is an important part of the network involved in verb retrieval, noun retrieval is most strongly mediated by temporo-parietal circuitry and depends far less on prefrontal function (Damasio \& Tranel, 1993; Daniele, Silveri, Giustolisi \& Gainotti et al., 1993, Shapiro, Mottaghy, \& Schiller, 2005). The exact link between prefrontal dysfunction and verb deficits is, however, a matter of debate.

Three theories have been proposed: a motor, a grammatical and an executive hypothesis. A first line of interpretation is based on the observation that perception of action verbs elicits a somatotopical 
activation of motor cortices in healthy persons (Hauk, Johnsrude, \& Pulervmüller, 2004). Since this activation is found to occur within the first $250 \mathrm{~ms}$ after word onset, some authors argue that motor cortices are an essential part of word meaning retrieval (Hauk \& Pulvermuller, 2004; Buccino, Riggio, Melli, Binkofski, Gallese, \& Rizzolatti, 2005; Gallese \& Lakoff, 2005; Tettamanti, Buccino, Saccuman, Gallese, Danna, \& Scifo, 2005). In this light verb production problems in PD reflect dysfunctions in accessing the mental representation of actions (Péran et al., 2003; Boulenger et al., 2008; Rodriguez-Ferreiro et al., 2009; Herrera \& Cuetos, 2012). However, disagreement exists on the interpretation of this motor activation. According to other authors, it is only a consequence of nonspecific spreading of activation from language to motor areas (Tokimura, Borroni, Isaja, \& Rumiato, 1996; Hickok, 2010). Moreover, even authors supporting the motor theory acknowledge that the contribution of motor regions to action word understanding may be relatively small (Boulenger et al., 2008). In the present study PD patients produced all sorts of verbs, not only action verbs. Taken together, the present results do not offer strong support for this hypothesis.

A second, grammatical theory is based on the suggestion that the left prefrontal cortex is engaged in processing verbs as a grammatical class (Shapiro, Pascual-Leone, Mottaghy, Gangitano, \& Caramazza, 2001). However, there is increasing evidence that grammatical class per se is not an organizational principle of knowledge in the brain. Rather semantic/pragmatic and distributional cues in language would distinguish between both word classes (Vigliocco, Vinson, Druks, Barber, \& Cappa, 2010). In addition, the present study found no difference between PD patients and control participants in the proportion of verbs and nouns. If a grammatical impairment underlies the verb production deficit in PD patients (Péran et al., 2003), one would expect a decrease in the amount of verbs. Consequently, this second theory does not explain this result either.

A third and final theory links verb deficits to cognitive impairments. Language function in general is known to rely heavily on executive functions (Lewis et al., 1998). Verbs are more demanding on cognitive resources than nouns because they need the coordination and manipulation of a large variety of information (semantic and syntactic features, attribution of thematic roles) (Grossman, 1998; Silveri, Salvigni, Capp, Della Vedova, \& Puopolo, 2003). As a result, a deficit for verbs may not 
necessarily reflect a linguistic dysfunction, but rather a cognitive and/or executive impairment (Piatt et al., 1999; Silveri et al., 2003; Signorini \& Volpato, 2006; Cotelli et al., 2007; Colman et al., 2009). Since these processes are under control of prefrontal networks, they tend to be reduced in patients with a frontostriatal pathology (Owen, Doyon, Dagher, Sadikot, \& Evans, 1998). Indeed, cognitive and executive dysfunctions often occur in PD, even in the early stages of the disease (Lees \& Smith, 1983; Levin et al., 1989; Cooper et al., 1991; Dubois \& Pillon, 1997). In the present study, the verb deficit presented as a reduced TTR in notional verbs. TTR is a measure of lexical diversity which is not a pure language measure. It is influenced by cognition as well. In addition, this language variable differs significantly between PD patients with normal and poor verbal memory as measured by AVLT (Rey, 1964). Patients with reduced memory capacity show a reduced TTR. Consequently, a cognitive deficit may account for the present observation.

Verbal memory impairment has been suggested to play a major role in language deficits in PD patients. Its influence is especially important during sentence comprehension (Caplan \& Waters, 1999; Skeel, Crosson, Nadeeau, Algina, Bauer, \& Fennel, 2001; Hochstadt, Nakano, Lieberman, \& Friedman, 2006; Hochstadt, 2009; Colman, Koerts, Stowe, Leenders, \& Bastiaanse, 2011). Verb deficits have been linked to long-term memory impairment (Cotelli et al., 2007). In addition, a strong correlation between verbal working memory and verb deficits was observed in a recent study using a picture-sentence task (Colman et al., 2009). In conclusion, verbal memory impairments are likely to have a negative influence on the lexical diversity in notional verbs.

However, an additional influence of executive dysfunctions cannot be excluded. Executive functions and memory show a high degree of overlap. Verbal memory and executive functions are estimated to share more than $50 \%$ of variance in the general population (Duff, Schoenberg, Scott, \& Adams, 2005). In PD patients, a vital role of executive functions in memory impairments has been shown as well (O'Brien, Wadley, Nicholas, Stover, Watts, \& Griffith, 2009). Moreover, additional functions such as attention, set-switching, inhibition, fluency and abstract sequencing abilities are thought to be relevant for sentence processing (Colman et al., 2009). In PD, especially set-switching impairments have been mentioned to correlate with sentence comprehension (Grossman, Carvel, Gollomp, Stern, Reivich \& 
Morrison, 1993; Kemmerer, 1999; Grossman, Lee, Morris, Stern, \& Hurtig, 2002; Hochstadt et al., 2006; Hochstadt, 2009; Colman et al., 2011), grammatical errors (Zanini et al., 2010), verbal fluency deficits (Gotham, Brown, \& Marsden, 1988; Downes, Sharp, Costall, Sagar \& Howe, 1993; Troyer, Muscovitch, Winocur, Leach, \& Freedman, 1998) and even verb production problems (Colman et al., 2009). Moreover, some of these studies report a correlation with verbal memory as well, which emphasizes the link between both functions in PD (Grossman et al., 2002; Hochstadt et al., 2006; Colman et al., 2009; Hochstadt, 2009; Colman et al., 2011). In the present study, set-shifting may have had an influence on the TTR of notional verbs as well. Shifting processes demand cognitive flexibility. A previous irrelevant response should be inhibited while a new response should be selected and planned (Marsden \& Obeso, 1994). When this flexibility is disturbed, less variety in language samples can be expected. One might argue against this hypothesis by saying that this flexibility did not affect TTR of nouns. However, since verbs are more demanding on both language and cognitive resources (Grossman, 1998), they are more vulnerable than nouns for the potential impact of set-switching problems (Genter, 1991; Silveri et al., 2003).

In addition, advanced PD patients generated more semantic perseverations than the normal control participants. A decrease in informativeness of sentences has been reported in PD (Cummings et al., 1988; Murray, 2000). In these studies, however, semantic perseverations were only a part of what was considered informative. Bayles et al., (1985) evaluated the occurrence of verbal perseverations in a similar manner as the present study. During an object description task, perseverative responses were found in demented patients with different degenerative pathologies (PD among others). The present results show that semantic perseverations can occur even in non-demented PD patients. Since perseverations are observed in different pathologies, they can not be associated with damage to a specific brain region or a particular disease process. Therefore, the cause of these phenomena is suggested to be multifactorial. Perseverative responses can develop due to a lack of cortical inhibition of previous ideas, persistent neuronal excitation, paucity of new ideas and/or impaired selecting from competing alternatives (Bayles et al., 1985). 
As mentioned before, inhibition of previous ideas and selection and planning of new ideas, is exactly what set-switching is about (Marsden \& Obeso, 1994). Shifting disorders have been shown to give rise to perseverations (McNamara \& Albert, 2004). Extensively reported motor and cognitive perseverations in PD are attributed to this executive dysfunction (Flowers \& Robertson, 1985; Ebersbach, Hattig, Schelosky, Wissel \& Poewe, 1994; Cools, Barker, Sahakian \& Robbins, 2001; Stoffers, Berendse, Deijen, \& Wolters, 2001; Herzog, Möller, Witt, Pinsker, Deuschl, \& Volkmann, 2009). As language is neurologically intertwined with cognition and motor control (Lieberman, 2000, 2006), it seems logical that perseverations in the language domain have the same origin. In the present study, no language variable differed between PD patients with a good and impaired interference score, as measured by SCWT (Stroop, 1935; Hammes, 1978). This inference score can be seen as a measure of inhibition (Lezak \& Loring, 2004; Strauss et al. 2006). Consequently, problems of inhibition do not seem to have an influence on language in this task. Since set-switching requires more than inhibition alone (Marsden \& Obeso, 1994; Miyake, Friedman, Emerson, Witzki, Howerter, \& Wager, 2000), this lack in difference can not exclude a possible influence of set-shifting. In addition, considering the overlap between memory and different executive dysfunctions (Duff et al., 2005), other cognitive aspects may have played a role as well. Perhaps the cognitive processes enabling individuals to generate ideas are impaired. To evaluate this issue, future research on language in PD should include a large battery of neuropsychological tests.

A remarkable trend was found in the comparison between early and advanced PD patients. Advanced PD patients produced more verbs than PD patients in an early phase. This observation may seem contradictory with the decreased TTR of notional verbs in the comparison between advanced PD patients and control participants. However, this is not the case. TTR is a measure of lexical diversity which includes a large cognitive component as well as a grammatical and semantical component. Proportion of verbs is a measure for the amount of verbs, which has a lower intrinsic cognitive aspect. The Illes et al. $(1988,1989)$ studies observed an increase in lexical words in moderately compared to mildly impaired PD patients. Besides verbs, lexical words involve more word classes such as nouns and adjectives. Therefore, this increase is not necessarily due to an increase in verbs. In the present 
study no difference in the variable 'lexical words' was found. However, considering that the variable was 'proportion of verbs', the difference may have a link to another word class that also differed in its proportion. Indeed, the variable 'proportion of nouns' yielded a reversed pattern. This difference, however, was not significant. Therefore, no statements will be made to explain this observation. Future studies including a more focused evaluation of verb and noun production, might yield additional insights into this issue.

Finally, two last remarks on the design of the present study should be mentioned. First, all PD patients continued their regular anti-parkinson medication during testing. Future studies might also include the evaluation of language in on- and off-conditions in order to appreciate the dopaminergic influence on language function, as previous results on this issue have yielded confounding results (Arnott, Chenery, Murdoch, \& Silburn, 2000; Murdoch, Arnott, Chenery, \& Silburn, 2000; Boulenger et al., 2008; Angwin, Arnott, Copland, Haire, Murdoch, Silburn et al., 2009; Colman et al., 2009). Secondly, PD is a very heterogeneous disease. Consequently, it can not be excluded that slight language abnormalities already manifest in some mildly affected PD patients and, conversely, that not all advanced PD patients have language alterations. In addition, daily life activities are more demanding on cognitive and executive functions than the present study. Moreover, everyday communication frequently occurs in less favourable conditions (background noise, time pressure, ...). All these variables should be kept in mind when applying the present results in clinical practice. It is important to approach every patient individually and to analyze his/her language skills profoundly. This will allow clinicians to provide appropriate compensation strategies to PD patients and effective communication strategies to caregivers (Colman, 2011).

\section{Conclusion}

Sentence generation abilities of PD patients were evaluated in a task specifically created for the present study. Demands on memory and attention were kept as low as possible to reduce a negative influence of these cognitive dysfunctions on language. Differences in language variables were observed in advanced PD patients compared to normal controls. Whether this is a consequence of a 
purely cognitive deterioration or reflects a language deterioration exacerbated by cognitive

2 degeneration, cannot be concluded from the present data. However, a negative impact of cognitive

3 dysfunctions may be important. The typical noun/verb dissociation, observed repeatedly in PD,

4 presented as a decreased lexical diversity in notional verbs, which was not seen in nouns. Besides a

5 language component, lexical diversity reflects a cognitive aspect as well. Therefore, cognitive

6 dysfunctions are hypothesized to be the cause of this observation. Verbal memory impairments

7 probably had a great influence. Furthermore, advanced PD patients also produced more semantic

8 perseverations. Since perseverations are partially caused by disturbed inhibition of a previous idea and

9 disturbed selecting and planning of a new response, set-switching is suggested to be linked to this

result. Considering the large overlap between memory and several executive functions, other cognitive aspects may have played a role as well. Therefore, future research on language in PD should include a comprehensive battery of neuropsychological tests.

\section{Declaration of interest}

The authors report no conflicts of interest.

\section{References}

Alexander, G., DeLong, M., \& Strick, P. (1986). Parallel organization of functionally segregated circuits linking basal ganglia and cortex. Annual Review of Neuroscience, 357-381.

Alves, G., Forsaa, E., Pedersen, K., Gjerstad, M., \& Larsen, J. (2008). Epidemiology of Parkinson's disease. Journal of Neurology, 18-32.

Angwin, A., Arnott, W., Copland, D., Haire, M., Murdoch, B., Silburn, P., et al. (2009). Semantic activation in Parkinson's disease patients on and off levodopa. Cortex, 950-959.

Altman, L., Troche, M. (2011). High-level language production in Parkinson's disease: a review.

Parkinson's disease, 1 - 12

Arnott, W., Chenery, H., Murdoch, B., \& Silburn, P. (2000). Dopaminergic modulation of semntic memory via centre-surround attentional processing: evidence from Parkinson's disease. Asia Pacific Journal of Speech, Language and Hearing, 123-128. 
Azuma, T., Bayles, K., Cruz, R., Tomoeda, C., Wood, J., McGeagh, A., et al. (1997). Comparing the difficulty of letter, semantic and name fluency tasks for normal elderly and patients with Parkinson's disease. Neuropsychology, 488-497.

Bastiaanse, R., \& Leenders, K. (2009). Language and Parkinson's disease. Cortex , 912-914.

Bayles, K. A. (1990). Language and Parkinson disease. Alzheimer Disease And Associated Disorders, 171-180.

Bayles, K., Tomoeda, C., Kaszniak, A., Stern, L., \& Eagans, K. (1985). Verbal perseveration of dementia patients. Brain and Language, 102-116.

Bayles, K., Tomoeda, C., Wood, J., Cruz, R., Azuma, T., \& Montgomery, E. (1997). The effect of Parkinson's disease on language. Journal of Medical Speech-Language Pathology, 157-166.

Berg, E., Björnram, C., Hartelius, L., Laakso, K., \& Johnels, B. (2003). High-level language difficulties in Parkinson's disease. Clinical Linguistics \& Phoniatrics , 63-80.

Bonta, E., \& Sistermans-Theunisse, J. (1993). Logotherapia: taaltherapie voor afasiepatiënten: een linguistisch oefenprogramma. Swets-Zeitlinger.

Boulenger, V., Mechtouff, L., Thobois, S., Broussolle, E., Jeannerod, M., \& Nazir, T. (2008). Word processing in Parkinson's disease is impaired for action verbs but not for concrete nouns. Neuropsychologia , 743-756.

Boxum, E., \& Zwaga, M. (2007, Novembre 12). Analyse voor Spontane Taal bij Afasie. Retrieved 2009, from website of Vereniging voor Klinische Linguistiek: www.klinische-linguistiek.nl

Brown, R., \& Marsden, C. (1988). Internal versus external cues and the control of attention in Parkinson's disease. Brain, 323-345.

Buccino, G., Riggio, L., Melli, G., Binkofski, F., Gallese, V., \& Rizzolatti, G. (2005). Listening to action-related sentences modulates the activity of the motor system: a combined TMS and behavioral study. Cognitive Brain Research, 355-363.

Caballol, N., Marti, M. J., \& Tolosa, E. (2007). Cognitive dysfunction and dementia in Parkinson's disease. Movement Disorders , 358-366.

Caplan, D., \& Waters, G. (1999). Verbal working memory and sentence comprehension. Behavioral and Brain Sciences , 77-126.

Cohen, J. (1988). Statistical power analysis for the behavioral sciences. Hillsdale, New Jersey: Erlbaum.

Colman, K. (2011). Dissertation: Behavioral and neuroimaging studies on language processing in Dutch speakers with Parkinson's disease. Ridderkerk: Ridderprint.

Colman, K., Koerts, J., Stowe, L., Leenders, K., \& Bastiaanse, R. (2011). Sentence comprehension and its association with executive functions in patients with Parkinson's disease. Parkinson's Disease .

Colman, K., Koerts, J., van Beilen, M., Leenders, K., Post, W., \& Bastiaanse, R. (2009). The impact of executive functions on verb production in patients with Parkinson's disease. Cortex , 930-942. 
Contarino, M., Daniele, A., Sibilia, A., Romito, L., Bentivoglio, A., Gianotti, G., et al. (2007). Cognitive outcome 5 years after bilateral chronic stimulation of subthalamic nucleus in patients with Parkinson's disease. Journal of Neurology, Neurosurgery and Psychiatry, 248-252.

Cotelli, M., Borroni, B., Manenti, R., Zanetti, M., Arévalo, A., Cappa, S., et al. (2007). Action and object naming in Parkinson's disease without dementia. European Journal of Neurology, 632-637.

Cools, R., Barker, R., Sahakian, B., \& Robbins, T. (2001). Mechanisms of cognitive set flexibility in Parkinson's disease. Brain , 2503-2512.

Cooper, J., Sagar, H., Jordan, N., Harvey, N., \& Sullivan, E. (1991). Cognitive impairment in early, untreated Parkinson's disease and its relationship to motor disability. Brain , 2095-2122.

Cummings, J., Darkins, A., Mendez, M., Hill, M., \& Benson, D. (1988). Alzheimer's disease and Parkinson's disease: comparison of speech and language alterations. Neurology, 680-684.

de Rijk, M., Breteler, M., Graveland, G., Ott, A., Grobbee, D., van der Meché, F., et al. (1995). Prevalence of Parkinson's disease in the elderly: the Rotterdam Study. Neurology , 2143-2146.

Damasio, A., \& Tranel, D. (1993). Nouns and verbs are retrieved with differently distributed neural systems. Proceedings of the National Academy of Science , 4957-4960.

Daniele, A., Silveri, M., Giustolisi, L., \& Gainotti, C. (1993). Category-specific deficits for grammatical classes of words: evidence for possible anatomical correlates. Italian Journal of Neurological Sciences , 87-94.

Downes, J., Sharp, H., Costall, B., Sagar, H., \& Howe, J. (1993). Alternating fluency in Parkinson's disease. Brain , 887-902.

Dubois, B., \& Pillon, B. (1997). Cognitive deficits in Parkinson's disease. Journal of Neurology, 2-8.

Dujardin, K., Defebvre, L., Krystkowiak, P., Blond, S., \& Destée, A. (2001). Influence of chronic bilateral stimulation of the subthalamic nucleus on cognitive function in Parkinson's disease. Journal of Neurology, 603-611.

Duff, K., Schoenberg, M., Scott, J., \& Adams, R. (2005). The relationship between executive functioning and verbal and visual learning and memory. Arch Clin Neuropsychol, 111-122.

Ebersbach, G., Hattig, H., Schelosky, L., Wissel, J., \& Poewe, W. (1994). Perseverative motor behavior in Parkinson's disease. Neuropsychologia , 799-804.

Elgh, E., Domellöf, M., Linder, J., Edström, M., Stenlud, H., \& Forsgren, L. (2009). Cognitive function in early Parkinson's disease: a population-based study. European Journal of Neurology, 1278-1284.

Flohil-v.d. Scheer, F., Zwaga, M., \& Jonkers, R. (2011). Normering van de ASTA, Analyse voor Spontane Taal bij Afasie. Stem-, Spraak- en Taalpathologie, 19-30.

Flowers, K., \& Robertson, C. (1985). The effect of Parkinson's disease on the ability to maintain a mental set. Journal of Neurology, Neurosurgery and Psychiatry, 517-529. 
Flowers, K., Robertson, C., \& Sheridan, M. (1995). Some characteristics of word fluency in Parkinson's disease. Journal of Neurolinguistics , 33-46.

Folstein, M., Folstein, S., \& McHugh, P. (1975). "Mini-mental state". A practice method for grading the cognitive state of patients for the clinician. Journal of Psychiatric Research, 189-198.

Funkiewiez, A., Ardouin, C., Caputo, E., Krack, P., Fraix, V., Klinger, H., et al. (2004). Long term effects of bilateral subthalamic nucleus stimulation on cognitive function, mood and behavior in Parkinson's disease. Journal of Neurology, Neurosurgery and Psychiatry, 834-839.

Gallese, V., \& Lakoff, G. (2005). The brain's concepts: the role of sensory-motor system in reason and language. Cognitive neuropsychology, 455-479.

Gelb, D., Oliver, E., \& Gilman, S. (1999). Diagnostic Criteria for Parkinson Disease. Archives of Neurology, 33-39.

Genter, D. (1991). Some interesting differences between verbs and nouns. Cogn Brain Theory, 161178.

Gotham, A., Brown, R., \& Marsden, C. (1988). "Frontal" cognitive function in patients with Parkinson's disease "on" and "off" levodopa. Brain , 299-321.

Grossman, M. (1998). Not all words are created equal. Neurology, 324-325.

Grossman, M. (1999). Sentence processing in Parkinson's disease. Brain and Cognition, 387-413.

Grossman, M., Carvel, S., Gollomp, S., Stern, M., Reivich, M., \& Morrison, D. (1993). Cognitive and physiological substrates of impaired sentence processing in Parkinson's disease. Journal of Cognitive Neuroscience, 480-498.

Grossman, M., Cooke, A., DeVita, C., Lee, C., Alsop, D., Detre, J., et al. (2003). Grammatical and resource components of sentence processing in Parkinson's disease: an fMRI study. Neurology, 775781.

Grossman, M., Lee, C., Morris, J., Stern, M., \& Hurtig, H. (2002). Assessing resource demands during sentence processing in Parkinson's disease. Brain and Language, 603-616.

Hammes, J. (1978). De Stroop Kleur-Woord Test. Nederland: Harcourt Test Publishers.

Hauk, O., \& Pulvermüller, F. (2004). Neurophysiological distinction of action words in the frontocentral cortex. Human Brain Mapping, 191-201.

Hauk, O., Johnsrude, I., \& Pulvermüller, F. (2004). Somatotopic representation of action words in human motor and premotor cortex. Neuron, 301-307.

Herrera, E., \& Cuetos, F. (2012). Action naming in Parkinson's disease on/off dopamine. Neuroscience Letters , 219-222.

Herzog, J., Möller, B., Witt, K., Pinsker, M., Deuschl, G., \& Volkmann, J. (2009). Influence of subthalamic deep brain stimulation versus levodopa on motor perseverations in Parkinson's disease. Movement Disorders , 1206-1210. 
Hickok, G. (2010). The role of mirror neurons in speech perception and action word semantics. Language and cognitive processes , 749-776.

Hochstadt, J., Nakano, H., Lieberman, P., \& Friedman, J. (2006). the roles of sequencing and verbal working memory in sentence comprehension deficits in Parkinson's disease. Brain and Language, 243-257.

Hochstadt, J. (2009). Set-shifting and the on-line processing of relative clauses in Parkinson's disease: results from a novel eye-tracking method. Cortex , 991-1011.

Hoehn, M., \& Yahr, M. (1967). Parkinsonism: onset, progression and mortality. Neurology, 427-442.

Illes, J., Metter, E., Hanson, W., \& Iritani S. (1988). Language production in Parkinson's disease: acoustic and linguistic considerations. Brain and Language, 146-160.

Illes, J. (1989). Neurolinguistic features of spontaneous language production dissociate three forms of neurodegenerative disease: Alzheimer's, Huntington's and Parkinson's. Brain and Language , 628-642.

Jankovic, J. (2008). Parkinson's disease: clinical features and diagnosis. Journal of Neurology, Neurosurgery and Psychiatry, 368-376.

Kemmerer, D. (1999). Impaired comprehension of raising-to- subject constructions in Parkinson's disease. Brain and Language, 311-328.

Lees, A., \& Smith, E. (1983). Cognitive deficits in the early stages of Parkinson's disease. Brain, 257270.

Levin, B., Labre, M., \& Weiner, W. (1989). Cognitive impairments associated with early Parkinson's disease. Neurology, 557-561.

Lewis, F., LaPointe, L., Murdoch, B., \& Chenery, H. (1998). Language impairment in Parkinson's disease. Aphasiology , 193-206.

Lezak, M., \& Loring, H. (2004). Neuropsychological assessment, fourth edition. New York: Oxford University Press.

Lieberman, P. (2000). Human language and our reptilian brain: the subcortical bases of speech, syntax and thought. Cambridge: Harvard University Press.

Lieberman, P. (2006). Toward an evolutionary biology of language. Cambridge: Harvard University Press.

Lieberman, P., Friedman, J., \& Feldman, L. (1990). Syntax comprehension deficits in Parkinson's disease. The Journal of Nervous and Mental Disease, 360-365.

Marsden, C., \& Obeso, J. (1994). The functions of the basal ganglia and the paradox of the stereotaxic surgery in Parkinson's disease. Brain, 877-897.

McNamara, P., Krueger, M., O'Quin, K., Clark, J., \& Durso, R. (1996). Grammaticality judgments and sentence comprehension in Parkinson's disease: a comparison with Broca's aphasia. International Journal of Neuroscience, 151-166. 
McNamara, P., \& Durso, R. (2003). Pragmatic communication skills in patients with Parkison's disease. Brain and Language , 414-423.

McNamara, P., \& Albert, M. (2004). Neuropharmacalogy of verbal perseverations. Seminars in speech and language, 309-321.

Merola, A., Zibetti, M., Angrisano, S., Rizzi, L., Ricchi, V., Artusi, C., et al. (2011). Parksinon's disease progression at 30 years: a study of subthalamic deep brain-stimulated patients. Brain , 20742084.

Miatton, M., Wolters, M., Lannoo, E., \& Vingerhoets, G. (2004). Updated and extended flemish normative data of commonly used neuropsychological tests. Psychologica Belgica , 189-216.

Miyake, A., Friedman, N., Emerson, M., Witzki, A., Howerter, A., \& Wager, T. (2000). The unity and diversity of executive functions and their contributions to complex "frontal lobe" tasks: a latent variable analysis. Cognitive psychology, 49-100.

Moran, M. (2003) Arguments for rejecting the sequential Bonferroni in ecological studies. Oikos, 403405.

Morgante, L., Rocca, W., Di Rosa, A., De Domenico, P., Grigoletto, F., Meneghini, F., et al. (1992). Prevalence of Parkinson's disease and other types of parkinsonism: a door-to-door survey in three Sicilian municipalities. The Sicilian Neuro-Epidemiologic Study (SNES) Group. Neurology, 19011907.

Murdoch, B., Arnott, W., Chenery, H., \& Silburn, P. (2000). Dopaminergic modulation of semantic activation: evidence form Parkinson's disease. Brain and Language , 356-359.

Murray, L., \& Stout, J. (1999). Discourse comprehension in Huntington's and Parkinson's disease . American Journal of Speech-Language Pathology, 137-148.

Murray, L. L. (2000). Spoken language production in Huntington's and Parkinson's disease. American Speech-Language-Hearing Association, 1350-1366.

Murray, L. L., \& Lenz, L. P. (2001). Productive syntax abilities in Huntington's and Parkinson's diseases. Brain and Cognition , 213-219.

Muslimovic, D., Post, B., Speelman, J., \& Schmand, B. (2005). Cognitive profile of patients with newly diagnosed Parkinson's disease. Neurology, 1239-1245.

Nakagawa, S. (2004). A farewell to Bonferroni: the problems of low statistical power and publication bias. Behavioral Ecology, 1044-1045.

Owen, A., Doyon, J., Dagher, A., Sadikot, A., \& Evans, A. (1998). Abnormal basal ganglia outflow in Parkinson's disease identified with PET. Implications for higher cortical functions. Brain, 949-965.

O'Brien, T., Wadley, V., Nicholas, A., Stover, N., Watts, R., \& Griffith, H. (2009). The contribution of executive control on verbal-learning impairment in patients with Parkinson's disease with demantia and Alzheimer's disease. Arch Clin Neuropsychol , 237-244. 
Péran, P., Rascol, O., Démonet, J.-F., Celsis, P., Nespoulous, J.-L., Dubois, B., et al. (2003). Deficit of verb generation in nondemented patients with Parkinson's disease. Movement Disorders , 150-156.

Perneger, T. (1998). What's wrong with Bonferroni adjustments. British Medical Journal, 1236-1238.

Piatt, A., Fields, J., Paolo, A., Koller, W., \& Tröster, A. (1999). Lexical, semantic and action verbal fluency in Parkinson's disease with and without dementia. Journal of Clinical and Experimental Neuropsychology, 435-443.

Piovezan, M., Teive, H., Piovesan, E., Mader, M., \& Werneck, L. (2007). Cognitive function assessment in idiopathic Parkinson's disease. Arquivos de neuro-psiquiatria , 942-946.

Raskin, S., Sliwinski, M., \& Borod, J. (1992). Clustering strategies on tasks of verbal fluency in Parkinson's disease. Neuropsychologia , 95-99.

Reid, W., Hely, M., Morris, J., Loy, C., \& Halliday, G. (2012). Dementia in Parkinson's disease: a 20 year neuropsychological study (Sydney Multicentre Study). J Neurol Neurosurg Psychiatry, 10331037.

Rey, A. (1964). L'examen clinique en psychologie. Paris: Presses Universitaires de France.

Rodriguez-Ferreiro, J., Menendez, M., Ribacoba, R., \& Cuetos, F. (2009). Action naming is impaired in Parkinson disease patients. Neuropsychologia , 3271-3274.

Samii, A., Nutt, J., \& Ransom, B. (2004). Parkinson's disease. Lancet , 1783-1793.

Shapiro, K., Mottaghy, F., \& Schiller, N. (2005). Dissociating neural correlates for nouns and verbs. NeuroImage , 1058-1067.

Shapiro, K., Pascual-Leone A., Mottaghy F., Gangitano M., Caramazza A. (2001) Grammatical distinctions in the left frontal cortex. J. Cogn. Neurosci, $713-720$.

Signorini, M., \& Volpato, C. (2006). Action Fluency in Parkinson's disease: a follow-up study. Movement Disorders , 467-472.

Silveri, M., Salvigni, B., Capp, A., Della Vedova, C., \& Puopolo, M. (2003). Impairment of verb processing in frontal variant-frontotemporal dementia: a dysexecutive symptom. Dementia and geriatric cognitive disorders , 296-300.

Skeel, R., Crosson, B., Nadeeau, E., Algina, J., Bauer, M., \& Fennell, E. (2001). Basal ganglia dysfunction, working memory, and sentence comprehension in patients with Parkinson's disease. Neuropsychologia , 962-971.

Small, J. A., Lyons, K., \& Kemper, S. (1997). Grammatical abilities in Parkinson's disease: evidence from written sentences. Neuropsychologia , 1571-1576.

Stoffers, D., Berendse, H., Deijen, J., \& Wolters, E. (2001). Motor perseveration is an early sign of Parkinson's disease. Neurology, 2111-2113.

Strauss, E., Sherman, E., \& Spreen, O. (2006). A compendium of neuropsychological tests. Administration, norms and commentary. 3rd edition. Oxford University Press. 
Stroop, J. (1935). Studies of interference in serial verbal reactions. Journal of Experimental Psychology, 643-662.

Takeshita, S., Kurisu, K., Trop, L., Arita, K., Akimitsu, T., \& Verhoeff, N. (2005). Effect of subthalamic stimulation on mood state in Parkinson's disease: evaluation of previous facts and problems. Neurosurgical Review, 179-186.

Tettamanti, M., Buccino, G., Saccuman, M., Gallese, V., Danna, M., \& Scifo, P. (2005). Listening to action-related sentences activates fronto-parietal motor circuits. Journal of Cognitive Neuroscience, 273-281.

Tokimura, B., Borroni, P., Isaja, A., \& Rumiati, R. (2005). THe role of primary motor cortex in mental rotation: a TMS study. Cognitive Neuropsychology, 348-363.

Trail, M., Fox, C., Olson Ramig, L., Sapir, S., Howard, J., \& Lai, E. C. (2005). Speech treatment for Parkinson's disease. Neuro Rehabilitation, 205-221.

Troyer, A., Muscovitch, M., Winocur, G., Leach, L., \& Freedman, M. (1998). Clustering and switching on verbal fluency tasks in Alzheimer's disease and Parkinson's disease. J Int Neuropshychol Soc , 137-143.

Vigliocco, G., Vinson, D., Druks, J., Barber, H., \& Cappa, S. (2010). Nouns and verbs in the brain: a review of behavioral, electrophysiological, neurophsychological and imaging studies. Neuroscience and Biobehavioral Reviews .

Whiting, E., Copland, D., \& Angwin, A. (2005). Verb and context processing in Parkinson's disease. Journal of Neurolinguistics , 259-276.

Williams-Gray, C., Foltynie, T., Brayne, C., Robbins, T., \& Barker, R. (2007). Evolution of cognitive dysfunction in an incident Parkinson's disease cohort. Brain, 1787-1798.

York, M., Dulay, M., Macias, A., Levin, H., Grossman, R., Simpson, R., et al. (2008). Cognitive declines following bilateral subthalamic nucleus deep brain stimulation for the treatment of Parkinson's disease. Journal of Neurology, Neurosurgery and Psychiatry, 789-795.

Zanini, S., Tavano, A., Fabbro, F. (2010). Spontaneous language production in bilingual Parkinson's disease patients: evidence of greater phonological, morphological and syntactic impairments in native language. Brain \& Language, 84 - 89

Ziemssen, T., \& Reichmann, H. (2007). Non-motor dysfunction in Parkinson's disease. Parkinsonism and Related Disorders , 323-332. 
1 Appendix A: The English translation of the text 'Mr. Meijer' and the lexical word cues that facilitate 2 the reproduction are presented.

4 It's Friday morning, 8 o'clock, and Mr. Meijer's alarmclock goes off.

5 He jumps out of bed, because normally he should be at the office already.

6 Mr. Meijer hurries to the bathroom to get washed, shaved and dressed.

7 In the meantime, his wife is waiting for him with his breakfast: two slices of buttered bread, an apple 8 and a banana.

9 Mr. Meijer takes his breakfast with him in his car and drives to the office, which is situated at the end 10 of the street.

11 His office is located in an apartment building, at the $13^{\text {th }}$ floor to be more precise.

12 When Mr. Meijer arrives at work, he sees that the elevator is out of use that day.

13 So he has to take the stairs, which makes Mr. Meijer even more late for work.

14 The stairs count 200 rungs, which causes a full five minutes' delay.

15 Taking the stairs is very tiring for him because his condition is weakened considerably. When Mr. Meijer finally shows up, his boss is already waiting for him, rather angry, since it is already the $3^{\text {th }}$ time in the same week that Mr. Meijer overslept himself.

\section{$\underline{\text { Cues }}$}

21

- alarmclock

- bathroom

23 - breakfast

24 - car

25 - apartment

26 - elevator

27 - stairs

$28-200$

29 - condition

30 - angry 
3

4 Example 1: male - age: 70 - Hoehn and Yahr: 4

5

7 Elevator: translation are presented. Perseverations are underlined.

Example 2: male - age: 75 - Hoehn and Yahr: 3

Stairs:

\section{Example 3: male - age: 63 - Hoehn and Yahr: 3}

Apartment:

200:

Angry: waiting for him op te wachten. 200 rungs all together. treden alle tesamen. again too late for work.

Appendix B: Some examples of perseverations. Both the original Dutch sentence and the English

Apartment: $\quad$ At the 13th floor he takes the elevator. It is out of use.

Op de $13^{e}$ verdieping neemt hij de lift. Die is ook stuk.

He takes the elevator. It is out of use.

Hij neemt de lift. Die is ook stuk.

The stairs were very heavy for him.

Condition: $\quad$ Because his condition was weakened, the stairs were very heavy for him. Daar zijn conditie verslecht was, vond hij de trap heel zwaar.

His office is in an apartment building at the 13th floor where his boss is

Zijn werk is in een flatgebouw op de $13^{e}$ verdieping waar zijn baas hem staat

The stairs of the apartment building where his office is at the 13th floor, has

De trap van het flatgebouw waar zijn werk op de $13^{e}$ verdieping ligt, is 200

Upstairs, his boss is madly waiting for him because he is angry because he is

Daarboven staat zijn baas hem boos op te wachten want hij is erg kwaad voor de zoveelste maal dat hij te laat op zijn werk komt. 
Table 1: Personal characteristics and cognitive results of all PD patients, PD patients in early and advanced stage and their control group (NC).

\begin{tabular}{|c|c|c|c|c|c|c|}
\hline & \multicolumn{2}{|c|}{ Whole group } & \multicolumn{2}{|c|}{ Initial stage } & \multicolumn{2}{|c|}{ Advanced stage } \\
\hline & $\mathrm{PD}$ & $\mathrm{NC}$ & PD & $\mathrm{NC}$ & $\mathrm{PD}$ & $\mathrm{NC}$ \\
\hline \multicolumn{7}{|l|}{ Personal characteristics } \\
\hline Number & 20 & 20 & 10 & 10 & 10 & 10 \\
\hline Age: mean (range) & $64.3(45-84)$ & $63.0(49-82)$ & $61.5(45-78)$ & $59.8(49-79)$ & $67.1(53-84)$ & $66.2(49-82)$ \\
\hline Male/female (number) & $10 / 10$ & $10 / 10$ & $5 / 5$ & $5 / 5$ & $5 / 5$ & $5 / 5$ \\
\hline \multicolumn{7}{|l|}{ Educational level (number) } \\
\hline - Primary education & 3 & 3 & 1 & 1 & 2 & 2 \\
\hline - Secondary education & 9 & 9 & 3 & 3 & 6 & 6 \\
\hline - Higher education & 8 & 8 & 6 & 6 & 2 & 2 \\
\hline \multirow{2}{*}{$\begin{array}{l}\text { Duration of PD in years : mean } \pm \text { SD } \\
\text { Hoehn and Yahr (number) }\end{array}$} & $8.1 \pm 6.7$ & l & $4.7 \pm 4.2$ & l & $11.4 \pm 7.1$ & l \\
\hline & l & l & $\begin{array}{l}\text { Stage 1: } 7 \\
\text { Stage 2: } 3\end{array}$ & l & $\begin{array}{l}\text { Stage 3: } 6 \\
\text { Stage 4: } 3 \\
\text { Stage 5: } 1\end{array}$ & l \\
\hline \multicolumn{7}{|l|}{ Cognitive results: mean $\pm S D$} \\
\hline MMSE & $27.3 \pm 1.6^{\mathrm{b}}$ & $28.8 \pm 1.0$ & $27.9 \pm 1.4$ & $28.8 \pm 1.1$ & $26.6 \pm 1.6^{\mathrm{b}}$ & $28.8 \pm 0.9$ \\
\hline $\begin{array}{l}\text { Stroop Color-Word Test } \\
\text { Interference score in percentiles }\end{array}$ & $38 \pm 29$ & $40 \pm 26$ & $47 \pm 30$ & $39 \pm 30$ & $28 \pm 26$ & $40 \pm 24$ \\
\hline AVLT & $22 \pm 24^{\mathrm{a}}$ & $55 \pm 35$ & $28 \pm 27$ & $62 \pm 33$ & $15 \pm 19^{a}$ & $48 \pm 37$ \\
\hline
\end{tabular}

Statistical analyses compared the scores of PD patients with the scores of the matched normal control group.

${ }^{\mathrm{a}}$ level of significance: $\alpha \leq 0.05 \quad{ }^{\mathrm{b}}$ level of significance: $\alpha \leq 0.01$ 
Table 2: Overview of mean and standard deviation (SD) of all language variables for the comparison between: 1) all PD patients and all normal control participants (NC) 2) PD patients in early stage and their matched NC 3) Advanced PD patients and their matched NC. P-value and Cohen's $d$ are reported as well.

\begin{tabular}{|c|c|c|}
\hline \multicolumn{3}{|c|}{ All PD patients vs all NC } \\
\hline & & p-value \\
\hline $\mathrm{NC}$ & PD & (Cohen's $d$ ) \\
\hline
\end{tabular}

\begin{tabular}{ccc}
\hline \multicolumn{3}{c}{ Early PD pat. vs matched NC } \\
\hline \multicolumn{2}{c}{ Mean \pm SD } & $\begin{array}{c}\text { p-value } \\
\text { NC }\end{array}$ \\
\hline
\end{tabular}

\begin{tabular}{|c|c|c|}
\hline \multicolumn{3}{|c|}{ Advanced PD pat. vs matched NC } \\
\hline \multicolumn{2}{|c|}{ Mean \pm SD } & \multirow{2}{*}{$\begin{array}{c}\mathrm{p} \text {-value } \\
(\text { Cohen's } d)\end{array}$} \\
\hline $\mathrm{NC}$ & PD & \\
\hline $8.64 \pm 1.92$ & $8.82 \pm 2.44$ & $0.96(0.08)$ \\
\hline
\end{tabular}

\section{MLU}

$9.07 \pm 1.85 \quad 8.62 \pm 2.04 \quad 0.25(0.23)$

$9.50 \pm 1.78 \quad 8.41 \pm 1.64 \quad 0.09(0.64)$

$$
0.18 \pm 0.03 \quad 0.18 \pm 0.03 \quad 0.73(0.03)
$$

$$
0.18 \pm 0.04 \quad 0.17 \pm 0.03 \quad 0.56(0.28)
$$

$0.18 \pm 0.02 \quad 0.19 \pm 0.03$

$0.23(0.39)$

$$
0.86 \pm 0.09 \quad 0.81 \pm 0.12 \quad 0.11(0.47)
$$$$
0.85 \pm 0.09 \quad 0.86 \pm 0.12 \quad 0.90(0.09)
$$$$
0.89 \pm 0.09 \quad 0.77 \pm 0.11
$$$$
0.01(1.19)^{b}
$$

notional verbs

$$
0.24 \pm 0.05 \quad 0.25 \pm 0.06 \quad 0.86(0.18)
$$$$
0.26 \pm 0.06 \quad 0.27 \pm 0.06 \quad 0.90(0.17)
$$$$
0.23 \pm 0.04 \quad 0.22 \pm 0.05
$$$$
0.57(0.22)
$$

of nouns

$$
0.81 \pm 0.13 \quad 0.77 \pm 0.16 \quad 0.51(0.27)
$$$$
0.74 \pm 0.12 \quad 0.78 \pm 0.17 \quad 0.59(0.27)
$$$$
0.87 \pm 0.10
$$$$
0.76 \pm 0.16
$$$$
0.07(0.82)
$$

$0.95 \pm 0.08 \quad 0.86 \pm 0.23 \quad 0.35(0.52)$

Prop. gramm. correct sent.

$$
0.95 \pm 0.08 \quad 0.86 \pm 0.23 \quad 0.35(0.52)
$$$$
0.95 \pm 0.08 \quad 0.82 \pm 0.28 \quad 0.35(0.63)
$$$$
0.95 \pm 0.07
$$

$0.90 \pm 0.16$

$0.70(0.40)$

Proportion of

lexical words

$$
0.58 \pm 0.04 \quad 0.61 \pm 0.03
$$$$
0.11(0.85)
$$$$
0.59 \pm 0.04
$$$$
0.61 \pm 0.03 \quad 0.32(0.57)
$$$$
0.58 \pm 0.05 \quad 0.60 \pm 0.03
$$$$
0.32(0.49)
$$

Proportion of complex sent.

$$
0.34 \pm 0.20 \quad 0.35 \pm 0.19 \quad 0.96(0.05)
$$$$
0.33 \pm 0.18 \quad 0.33 \pm 0.21 \quad 0.75(0.02)
$$$$
0.34 \pm 0.22
$$$$
0.37 \pm 0.19
$$

$0.67(0.15)$

Prop. sem. perseverations

$$
0.02 \pm 0.04 \quad 0.09 \pm 0.10 \quad \mathbf{0 . 0 0 5}(\mathbf{0 . 9 2})^{\mathrm{b}}
$$

$0.03 \pm 0.04 \quad 0.07 \pm 0.08 \quad 0.20(0.63)$

$0.01 \pm 0.03$

$0.12 \pm 0.12$

$0.01(1.26)^{b}$

${ }^{\mathrm{a}}$ level of significance $\alpha \leq 0.05^{\mathrm{b}}$ level of significance $\alpha \leq 0.01$. The absolute value of Cohen' $d$ is presented. For every comparison, the better scoring group can be determined based on the average scores. Interpretation of effect size: $|d|=0.20,0.50$ and 0.80 corresponds with small, medium and large effects respectively (Cohen, 1988). 
Table 3: Overview of mean and standard deviation (SD) of all language variables for the comparison between: 1) PD patients in early and advanced stage 2) PD patients with a normal $(n=7)$ and weak $(n=12)$ interference score on the SCWT 3) PD patients with a normal $(n=13)$ and impaired ( $n=7)$ score on the AVLT. P-value and Cohen's $d$ are reported as well.

\begin{tabular}{|c|c|c|c|c|c|c|c|c|c|}
\hline & \multicolumn{3}{|c|}{ Early vs advanced PD patients } & \multicolumn{3}{|c|}{ SCWT } & \multicolumn{3}{|c|}{ AVLT } \\
\hline & \multicolumn{2}{|c|}{ Mean \pm SD } & \multirow{2}{*}{$\begin{array}{c}\text { p-value } \\
\text { (Cohen's d) }\end{array}$} & \multicolumn{2}{|c|}{ Mean \pm SD } & \multirow{2}{*}{$\begin{array}{c}\text { p-value } \\
\text { (Cohen's d) }\end{array}$} & \multicolumn{2}{|c|}{ Mean \pm SD } & \multirow{2}{*}{$\begin{array}{c}\text { p-value } \\
\text { (Cohen's d) }\end{array}$} \\
\hline & Early & Adv. & & Normal & Impaired & & Normal & Impaired & \\
\hline MLU & $8.41 \pm 1.64$ & $8.82 \pm 2.44$ & $0.70(0.20)$ & $8.67 \pm 2.35$ & $8.51 \pm 2.01$ & $0.85(0.07)$ & $8.38 \pm 1.90$ & $9.04 \pm 2.36$ & $0.38(0.31)$ \\
\hline $\begin{array}{l}\text { Proportion } \\
\text { of verbs }\end{array}$ & $0.17 \pm 0.03$ & $0.19 \pm 0.03$ & $0.04(0.67)^{\mathrm{a}}$ & $0.17 \pm 0.03$ & $0.19 \pm 0.03$ & $0.54(0.67)$ & $0.18 \pm 0.02$ & $0.19 \pm 0.04$ & $0.48(0.32)$ \\
\hline $\begin{array}{l}\text { Type/token ratio } \\
\text { notional verbs }\end{array}$ & $0.86 \pm 0.12$ & $0.77 \pm 0.11$ & $0.09(0.78)$ & $0.82 \pm 0.15$ & $0.82 \pm 0.11$ & $0.98(0.03)$ & $0.86 \pm 0.12$ & $0.73 \pm 0.09$ & $0.01(1.23)^{\mathrm{b}}$ \\
\hline $\begin{array}{l}\text { Proportion } \\
\text { of nouns }\end{array}$ & $0.27 \pm 0.06$ & $0.22 \pm 0.05$ & $0.06(0.91)$ & $0.28 \pm 0.07$ & $0.23 \pm 0.05$ & $0.12(0.82)$ & $0.24 \pm 0.06$ & $0.25 \pm 0.07$ & $0.65(0.15)$ \\
\hline $\begin{array}{l}\text { Type/token } \\
\text { ratio nouns }\end{array}$ & $0.78 \pm 0.17$ & $0.76 \pm 0.16$ & $0.74(0.12)$ & $0.73 \pm 0.19$ & $0.78 \pm 0.15$ & $0.67(0.29)$ & $0.80 \pm 0.15$ & $0.71 \pm 0.18$ & $0.28(0.54)$ \\
\hline $\begin{array}{l}\text { Prop. gramm. } \\
\text { correct sent. }\end{array}$ & $0.82 \pm 0.28$ & $0.90 \pm 0.16$ & $0.70(0.35)$ & $0.74 \pm 0.28$ & $0.91 \pm 0.18$ & $0.09(0.72)$ & $0.83 \pm 0.26$ & $0.91 \pm 0.15$ & $0.82(0.38)$ \\
\hline $\begin{array}{l}\text { Proportion of } \\
\text { lexical words }\end{array}$ & $0.61 \pm 0.03$ & $0.60 \pm 0.03$ & $0.64(0.33)$ & $0.62 \pm 0.03$ & $0.60 \pm 0.03$ & $0.23(0.67)$ & $0.60 \pm 0.04$ & $0.61 \pm 0.03$ & $0.52(0.28)$ \\
\hline $\begin{array}{l}\text { Proportion of } \\
\text { complex sent. }\end{array}$ & $0.33 \pm 0.21$ & $0.37 \pm 0.19$ & $0.64(0.20)$ & $0.38 \pm 0.21$ & $0.32 \pm 0.20$ & $0.61(0.29)$ & $0.34 \pm 0.20$ & $0.38 \pm 0.20$ & $0.86(0.20)$ \\
\hline $\begin{array}{l}\text { Prop. sem. } \\
\text { perseverations }\end{array}$ & $0.07 \pm 0.08$ & $0.12 \pm 0.12$ & $0.34(0.49)$ & $0.10 \pm 0.15$ & $0.10 \pm 0.08$ & $0.63(0.03)$ & $0.06 \pm 0.08$ & $0.15 \pm 0.13$ & $0.13(0.83)$ \\
\hline
\end{tabular}

${ }^{\mathrm{a}}$ level of significance $\alpha \leq 0.05{ }^{\mathrm{b}}$ level of significance $\alpha \leq 0.01$

The absolute value of Cohen' $d$ is presented. For every comparison, the better scoring group can be determined based on the average scores. Interpretation of effect size: $|d|=0.20,0.50$ and 0.80 corresponds with small, medium and large effects respectively (Cohen, 1988). 
